\title{
Radiofrequency Catheter Ablation of Atypical Atrioventricular Nodal Reentrant Tachycardia
}

\author{
S. ADAM STRICKBERGER, M.D., STEVEN J. KALBFLEISCH, M.D., \\ BRIAN WILLIAMSON, M.D., K. CHING MAN, D.O., VICKEN VORPERIAN, M.D., \\ JOHN D. HUMMEL, M.D., JONATHAN J. LANGBERG, M.D., \\ and FRED MORADY, M.D.
}

From the Division of Cardiology, University of Michigan Medical Center, Ann Arbor, Michigan

\begin{abstract}
Ablation of Atypical Atrioventricular Nodal Reentrant Tachycardia. Introduction: Published reports of radiofrequency ablation of atypical atrioventricular nodal reentrant tachycardia (AVNRT) have been limited. We present our experience in 10 consecutive patients with atypical AVNRT who underwent radiofrequency ablation of the "slow" AV nodal pathway.

Methods and Results: There were 9 females and 1 male; their mean age was $44 \pm 19$ years $( \pm$ SD). The mean AVNRT cycle length and ventriculoatrial (VA) interval at the His position during AVNRT were $340 \pm 50 \mathrm{msec}$ and $200 \pm 70 \mathrm{msec}$, respectively. The slow pathway was successfully ablated in all patients with a mean of $10 \pm 7$ radiofrequency energy applications in the posteroseptal right atrium near the coronary sinus os. The mean procedure duration was $100 \pm 35$ minutes. There were no complications. In 4 patients, target sites were identified during sinus rhythm by mapping for possible slow pathway potentials. In the other 6 patients, target sites were identified by mapping retrograde atrial activation during AVNRT or ventricular pacing. The VA times at successful target sites were a mean of $\mathbf{4 5} \pm \mathbf{3 0} \mathrm{msec}$ less than the VA time at the His catheter during AVNRT. There were no differences in success rate, number of radiofrequency energy applications, or procedure duration between patients in whom mapping was guided by possible slow pathway potentials or by retrograde atrial activation. During $6 \pm 3$ months of follow-up, 1 patient had a recurrence of atypical AVNRT and underwent a second ablation procedure, which was successful.

Conclusion: Radiofrequency ablation of atypical AVNRT can be safely and effectively accomplished when target sites are identified based either on possible slow pathway potentials during sinus rhythm or retrograde atrial activation times during tachycardia. ( $J$ Cardiovasc Electrophysiol, Vol. 4, pp. 526-532, October 1993)
\end{abstract}

atypical atrioventricular nodal reentrant tachycardia, paroxysmal supraventricular tachycardia, radiofrequency ablation, retrograde atrial activation, slow pathway potentials, ventriculoatrial time

\section{Introduction}

Several studies ${ }^{1-5}$ have demonstrated the safety and efficacy of slow or fast pathway ablation using radiofrequency energy for atrioventric-

Address for correspondence: S. Adam Strickberger, M.D. $\sqrt{\text { Univer- }}$ sity of Michigan Medical Center, Division of Cardiology, 1500 East Medical Center Drive, UHB1F245, Ann Arbor, MI 481090022. Fax: 313-936-7641.

Manuscript received 21 January 1993; Accepted for publication 30 April 1993. ular nodal reentrant tachycardia (AVNRT). However, these reports have focused on the therapy of typical AVNRT, in which anterograde conduction occurs through a "slow" pathway and retrograde conduction occurs through a "fast" pathway. Only one prior report ${ }^{3}$ described the successful ablation of atypical AVNRT, in which the slow pathway serves as the retrograde limb of the reentry circuit, but this was only in 4 patients. We describe our experience in 10 consecutive patients with atypical AVNRT who underwent slow pathway ablation. 


\section{Methods}

\section{Patient Population}

The patient group consisted of 10 consecutive patients with atypical AVNRT who underwent radiofrequency ablation of the tachycardia at the University of Michigan Medical Center between May 1992 and April 1993.

The patient characteristics are described in Table 1. There were 9 females and 1 male; their mean age was $44 \pm 19$ years $( \pm$ SD). No patient had structural heart disease. The mean duration of symptoms was $14 \pm 13$ years, with a range of 2 weeks to 30 years. The patients had been treated with a mean of $2.4 \pm 2$ antiarrhythmic medications prior to referral.

\section{Electrophysiologic Testing}

Informed consent was obtained from all patients. Electrophysiologic tests were performed in the fasting state after all antiarrhythmic medications had been discontinued for at least 5 half-lives. Three 7 French quadripolar electrodes were inserted into the right femoral vein and positioned in the high right atrium, across the tricuspid valve to record the His-bundle electrogram, and in the right ventricle. The catheter across the tricuspid valve had a 4-mm distal electrode and a deflectable tip (EP Technologies, Inc., Mountain View, CA, USA, or Mansfield-Webster, Watertown, MA, USA) and was also used for ablation. Electrocardiographic leads $\mathrm{V}_{1}$, I, II, and sometimes III, and the intracardiac electrograms were displayed

TABLE 1

Patient Characteristics

\begin{tabular}{rcccc}
\hline $\begin{array}{l}\text { Patient } \\
\text { No. }\end{array}$ & Age & Sex & $\begin{array}{c}\text { Duration } \\
\text { of } \\
\text { Symptoms }\end{array}$ & $\begin{array}{c}\text { Frequency of } \\
\text { Symptoms } \\
\text { (per month) }\end{array}$ \\
\hline 1 & 50 & F & $25 \mathrm{y}$ & 12 \\
2 & 19 & F & 2 wk & 8 \\
3 & 32 & F & 1 mos & 2 \\
4 & 52 & M & $5 \mathrm{y}$ & 30 \\
5 & 37 & F & $10 \mathrm{y}$ & 1 \\
6 & 33 & F & $25 \mathrm{y}$ & 4 \\
7 & 64 & F & $30 \mathrm{y}$ & 6 \\
8 & 24 & F & 1 mos & 2 \\
9 & 63 & F & $27 \mathrm{y}$ & 4 \\
10 & 82 & F & 24 mos & 10 \\
\hline
\end{tabular}

$\mathrm{d}=$ day $; \mathrm{F}=$ female $; \mathrm{M}=$ male $;$ mos = months; wk = weeks; $\mathrm{y}=$ years. on an oscilloscope and recorded on a Mingograf 7 recorder (Siemens-Elema, Solna, Sweden). After the catheters were positioned, 3000 units of heparin was administered intravenously. Pacing was performed with a programmable stimulator (Bloom Associates, Reading, PA, USA).

The diagnostic portion of the electrophysiologic test was directed at measuring the conduction properties and refractory periods of the $\mathrm{AV}$ node, and inducing and determining the mechanism of the paroxysmal supraventricular tachycardia (PSVT). ${ }^{1}$ Incremental pacing and programmed stimulation were performed in the right atrium and right ventricle to define anterograde and retrograde AV nodal conduction and refractoriness and to confirm that atypical AVNRT could be provoked. If the PSVT could not be provoked in the baseline state, programmed stimulation was repeated during the infusion of 1 to $4 \mu \mathrm{g} / \mathrm{min}$ of isoproterenol. Tachycardia provoked by programmed stimulation was diagnosed as atypical AVNRT using previously established criteria. ${ }^{6}$

\section{Catheter Ablation Protocol}

Radiofrequency energy was delivered by a generator (EP Technologies, Inc.) that supplied a continuous, unmodulated sine wave output at a frequency of $500 \mathrm{kHz}$. Suitable target sites for slow pathway ablation were identified either during sinus rhythm or during atypical AVNRT or ventricular pacing. Mapping was performed in the low posterior right atrium, in the region of the coronary sinus os. When mapping was performed during sinus rhythm, target sites were identified by an atrial:ventricular electrogram ratio of $<1$ and by the presence of a possible slow pathway potential or a multicomponent atrial electrogram. ${ }^{2,3}$ When mapping was performed during atypical AVNRT or ventricular pacing, target sites were identified by searching for the site of earliest retrograde atrial activation. After a target site was identified, radiofrequency current was applied at 30 watts (W) for 10 to 30 seconds. The inducibility of atypical AVNRT was assessed after each application of radiofrequency energy. Thirty minutes after the final application of radiofrequency energy, atrial and ventricular pacing were repeated in the baseline state and during an infusion of isoproterenol to confirm that AVNRT could no longer be provoked.

In each patient, the total time and the fluoroscopic time for the procedure were recorded. 


\section{Follow-Up}

A follow-up electrophysiologic test was performed $5 \pm 7$ weeks after the ablation procedure in 3 patients. Anterograde and retrograde AV nodal conduction and refractoriness and the inducibility of atypical AVNRT were determined in the baseline state and during the infusion of isoproterenol. All patients were instructed to report any recurrence of symptoms suggestive of paroxysmal tachycardia.

\section{Statistical Analysis}

Continuous variables are expressed as mean \pm 1 standard deviation and were compared using the Student's $t$-test for paired or unpaired variables. $\mathrm{P}$ values $<0.05$ were considered statistically significant.

\section{Results}

\section{Overall Results}

The slow pathway was successfully ablated in all 10 patients with atypical AVNRT. The location of the successful site in all patients was in the low, posterior right atrium, near the coronary sinus os. The mean number of radiofrequency energy applications was $10 \pm 7$, and the mean power of the energy applications was $32 \pm 4 \mathrm{~W}$, respectively. The pre- and postablation electrophysiologic characteristics are described in Table 2. Before abla- tion, the mean atrio-His interval, the mean AV block cycle length, and the mean VA block cycle length were $85 \pm 20 \mathrm{msec}, 365 \pm 60 \mathrm{msec}$, and $320 \pm 95 \mathrm{msec}$, respectively. After the ablation procedure, these mean values did not change significantly. In this group of patients, 5 had dual AV nodal physiology noted before ablation. After ablation, dual AV nodal physiology was no longer present except in 1 patient during the infusion of isoproterenol.

\section{Mapping Techniques}

The slow pathway was localized during sinus rhythm in 4 patients and localized using VA activation time in 6 patients. The successful slow pathway ablation sites identified during sinus rhythm contained multicomponent atrial electrograms or possible slow pathway potentials (Fig. 1). Among the 6 patients in whom mapping was based on VA times, mapping was performed during PSVT in 5 patients and during ventricular pacing in one (Fig. 2 ). In these patients, the atrial electrogram recorded at the successful site often contained multiple components (Fig. 2). The mean local VA time in patients in whom the slow pathway was localized using the VA time was $200 \pm 70 \mathrm{msec}$ at the His-bundle catheter and $185 \pm 50 \mathrm{msec}$ at the successful target site ( $\mathrm{P}=0.03$; Table 3$)$. The VA time recorded using the ablation catheter was a mean of $45 \pm 30$ msec (range 20 to $110 \mathrm{msec}$ ) shorter than the VA time recorded using the His-bundle catheter.

TABLE 2

Electrophysiologic Characteristics Before and After Ablation

\begin{tabular}{|c|c|c|c|c|c|c|c|c|c|}
\hline \multirow{2}{*}{$\begin{array}{l}\text { Patient } \\
\text { No. }\end{array}$} & \multicolumn{4}{|c|}{ Baseline } & \multirow{2}{*}{$\begin{array}{c}\text { Atypical } \\
\text { AVNRT } \\
\text { CL }\end{array}$} & \multicolumn{4}{|c|}{ Postablation } \\
\hline & $\mathbf{A H}$ & AVB CL & AVN ERP & VAB CL & & AH & AVB CL & AVN ERP & VAB CL \\
\hline 1 & 70 & 300 & $210^{*}$ & 250 & 330 & 80 & 350 & 270 & 300 \\
\hline 2 & 70 & 320 & 240 & 400 & 380 & 70 & 340 & 220 & 440 \\
\hline 3 & 90 & 300 & 250 & 430 & 280 & 110 & 320 & $<220$ & 300 \\
\hline 4 & 80 & 360 & $290 *$ & 450 & 340 & 70 & 230 & $<170$ & 300 \\
\hline 5 & 80 & 320 & 270 & 280 & 350 & 90 & 260 & 180 & 500 \\
\hline $6 a$ & 90 & 410 & $290^{*}$ & $<200$ & 340 & 100 & 320 & 220 & 380 \\
\hline $6 \mathrm{~b} \dagger$ & 90 & 410 & $290^{*}$ & $<200$ & 340 & 80 & 320 & 190 & 340 \\
\hline 7 & 120 & 410 & $310^{*}$ & VAD & 330 & 110 & 410 & $330 * *$ & 350 \\
\hline 8 & 55 & 330 & 300 & 340 & 390 & 70 & 290 & 250 & 300 \\
\hline 9 & 70 & 360 & $250 *$ & 250 & 420 & 70 & 290 & $<160$ & 270 \\
\hline 10 & 110 & 480 & $\dagger$ & 400 & 450 & 85 & 450 & 360 & VAD \\
\hline Mean \pm SD & $85 \pm 20$ & $365 \pm 60$ & $275 \pm 25$ & $320 \pm 95$ & $340 \pm 50$ & $85 \pm 15$ & $325 \pm 65$ & $235 \pm 65$ & $350 \pm 75$ \\
\hline
\end{tabular}

All values are expressed in milliseconds. $\mathrm{AH}=$ atrial-His interval; $\mathrm{AVB} \mathrm{CL}=$ atrioventricular block cycle length; $\mathrm{AVN}$ $\mathrm{ERP}=$ atrioventricular nodal effective refractory period; AVNRT CL $=$ atrioventricular nodal reentrant tachycardia; SD = standard deviation; $\mathrm{VAB} C \mathrm{CL}=$ ventriculoatrial block cycle length; $\mathrm{VAD}=$ ventriculoatrial disassociation. *Dual $\mathrm{AV}$ nodal physiology noted during atrial extrastimulation; †Second ablation session for patient 6; **Dual AV nodal physiology noted only with atrial extrastimulation during isoproterenol infusion. † Incessant tachycardia prevented determination of AVN ERP. 

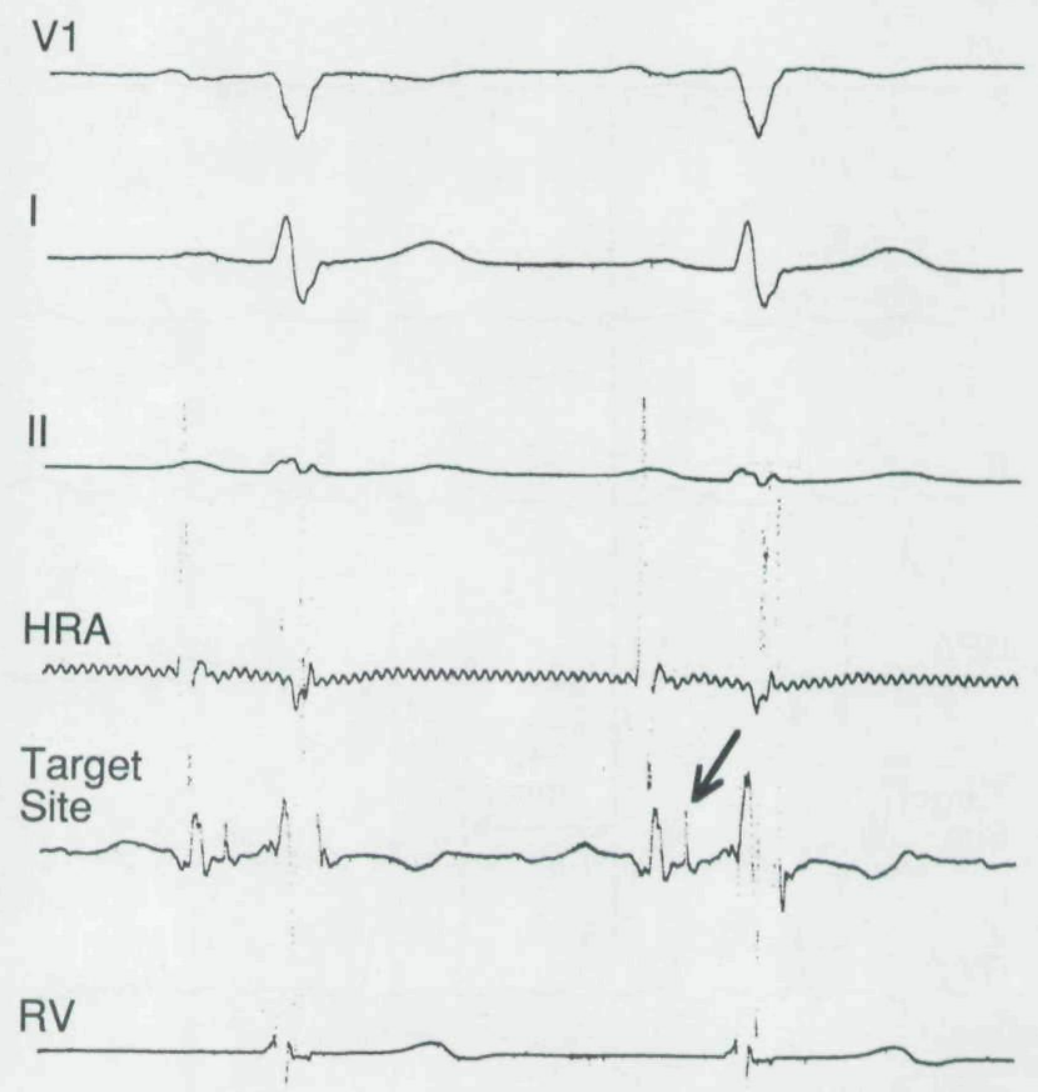

$500 \mathrm{msec}$

Figure 1. Electrocardiographic leads VI, I, and II, and intracardiac electrograms recorded from the high right atrium (HRA), the successful target site in the posteroseptal right atrium near the os of the coronary sinus, and the right ventricle $(R V)$ from patient 5 , in whom the slow pathway was localized during sinus rhythm. The arrow points to a presumed slow pathway potential. An application of radiofrequency energy at this site successfully eliminated slow pathway conduction.

\section{Follow-Up}

During a mean of $6 \pm 3$ months of follow-up, 9 patients had no recurrences of PSVT. One patient (number 6) had a recurrence of atypical AVNRT approximately 4 weeks after the initial ablation procedure and required a second ablation session. This patient's slow pathway was mapped using the VA activation time during both ablation procedures. The successful site of slow pathway ablation during the second ablation procedure was at the anterior lip of the coronary sinus os. None of the 3 patients who underwent follow-up electrophysiologic testing had inducible AVNRT.

\section{Complications and Procedure Duration}

The mean total procedural time and fluoroscopic time were $100 \pm 35$ minutes and $34 \pm 16$ min- utes, respectively. There were no differences in procedure duration, fluoroscopic time, or number of applications of radiofrequency energy between patients in whom the location of the slow pathway was mapped during sinus rhythm or based on VA time. There were no complications in any patients.

\section{Discussion}

\section{Main Findings}

This series of patients demonstrates that slow pathway ablation for atypical AVNRT can be safely and effectively accomplished and that ablation of atypical AVNRT can be guided either by possible slow pathway potentials during sinus rhythm or by mapping of retrograde atrial activation during tachycardia or ventricular pacing. 


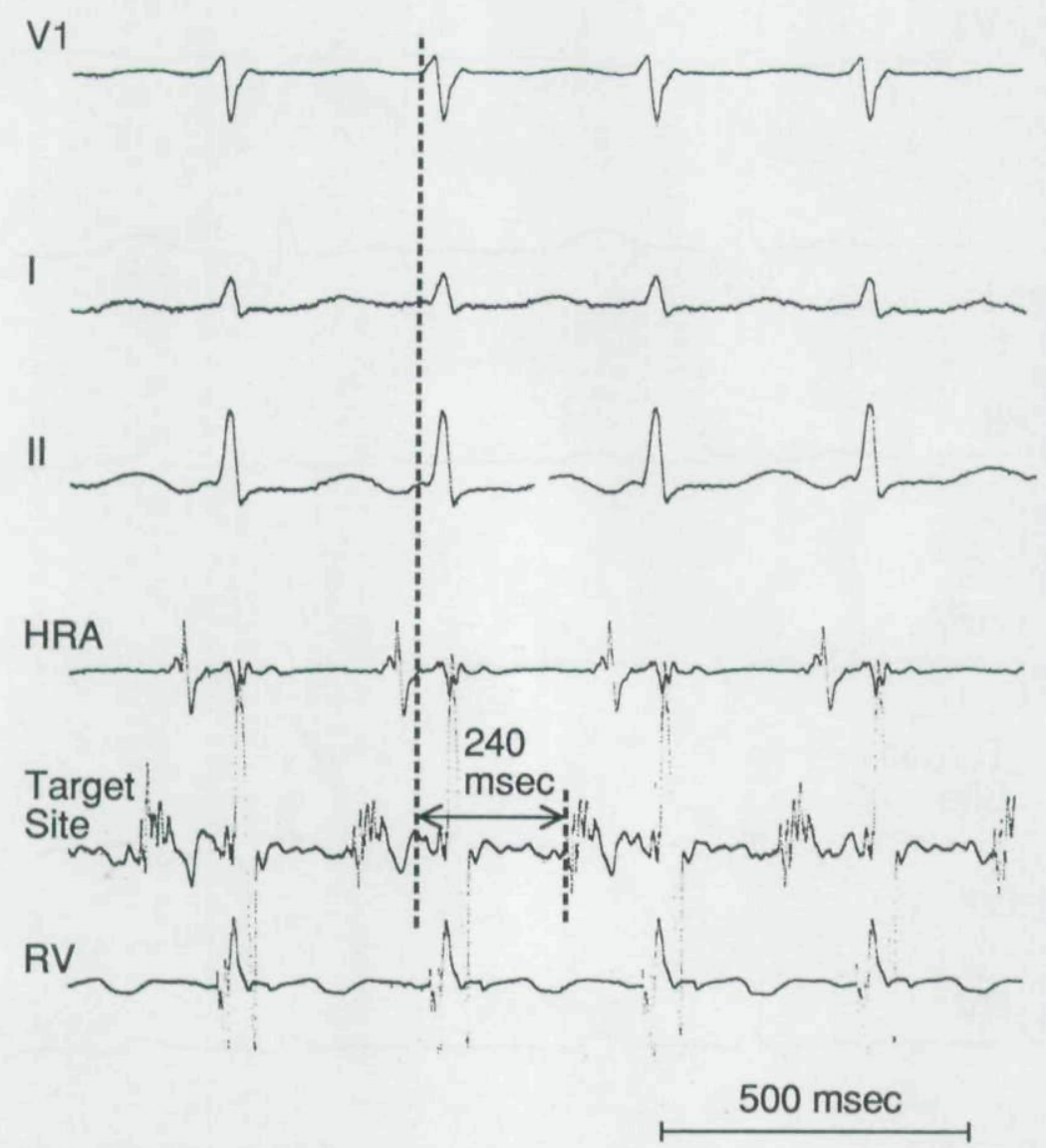

Figure 2. Recordings from the successful site of slow pathway ablation in patient 4 , in whom the slow pathway was localized during atypical AVNRT. The VA time is $240 \mathrm{msec}$ at the target site. The VA time recorded at the His-bundle catheter was 260 msec. Note the multicomponent atrial electrogram. An application of radiofrequency energy at this site in the posteroseptal right atrium near the coronary sinus os terminated the tachycardia and eliminated slow pathway conduction. Electrocardiographic leads VI, I, and II, and intracardiac electrograms recorded at the high right atrium (HRA), the target site, and the right ventricle $(R V)$ are shown.

\section{Mapping Techniques}

In some patients, successful target sites were localized during sinus rhythm using the previously reported technique of searching for possible slow pathway potentials or multicomponent atrial electrograms. ${ }^{2,3}$ In other patients, ablation of the slow pathway was guided by searching for the shortest VA time. We were not able to determine if one of these mapping techniques was superior to the other due to the small number of patients. However, there appeared to be no differences in the duration of the procedure, number of radiofrequency applications, success rates, or risk of recurrence.

When using retrograde atrial activation to map the location of the slow pathway, suc- cessful target sites had VA intervals 20 to 110 msec earlier than the VA interval recorded from the His-bundle catheter, and often the atrial electrogram contained multiple components. Therefore, potential target sites when using this technique should be at least $20 \mathrm{msec}$ earlier than the VA time at the His-bundle catheter.

\section{Electrophysiologic Findings}

As previously reported, ablation of the slow pathway did not result in any significant changes in AV or VA conduction except in patient 10 who developed VA dissociation after the ablation procedure. However, there were several patients in whom the AV block cycle length shortened after 


\begin{tabular}{|c|c|c|c|c|c|c|}
\hline \multicolumn{7}{|c|}{$\begin{array}{c}\text { TABLE } 3 \\
\text { Ablation Data }\end{array}$} \\
\hline $\begin{array}{l}\text { Patient } \\
\text { No. }\end{array}$ & $\begin{array}{c}\text { Mapping } \\
\text { Technique }\end{array}$ & $\begin{array}{c}\text { Acute } \\
\text { Success }\end{array}$ & $\begin{array}{c}\text { Atypical } \\
\text { AVNRT } \\
\text { Recurrence }\end{array}$ & $\begin{array}{c}\text { VA at HBE } \\
\text { During Atypical } \\
\text { AVNRT (msec) }\end{array}$ & $\begin{array}{c}\text { VA at } \\
\text { Successful } \\
\text { Site (msec) }\end{array}$ & $\begin{array}{c}\text { No. RF } \\
\text { Applications }\end{array}$ \\
\hline 1 & VA & Yes & No & 150 & 130 & 18 \\
\hline 2 & SPP & Yes & No & 130 & NA & 8 \\
\hline 3 & VA & Yes & No & NA & 200 & 10 \\
\hline 4 & VA & Yes & No & 260 & 240 & 8 \\
\hline 5 & SPP & Yes & No & 150 & NA & 27 \\
\hline $6 a$ & VA & Yes & Yes & 170 & 140 & 15 \\
\hline $6 b^{*}$ & VA & Yes & No & 170 & 130 & 4 \\
\hline 7 & SPP & Yes & No & 165 & NA & 6 \\
\hline 8 & VA & Yes & No & 340 & 230 & 7 \\
\hline 9 & SPP & Yes & No & 170 & NA & 4 \\
\hline 10 & VA & Yes & No & 250 & 210 & 2 \\
\hline Mean \pm SD & & & & $200 \pm 70$ & $180 \pm 50 \dagger$ & $10 \pm 7$ \\
\hline
\end{tabular}

*Second ablation session for patient 6; †Significantly less than VA recorded from HBE during AVNRT $(\mathrm{P}=0.03)$. AVNRT $=$ atrioventricular nodal reentrant tachycardia; HBE $=$ His-bundle recording; NA $=$ Not available; RF $=$ Radiofrequency ablation; $\mathrm{SD}=$ Standard deviation; $\mathrm{SPP}=$ Slow pathway potential; $\mathrm{SR}=\mathrm{Sinus}$ rhythm; VA = Ventriculoatrial interval.

ablation and 1 patient who had VA dissociation at baseline but a VA block cycle length of $330 \mathrm{msec}$ after ablation. These findings were likely due to changes in sympathetic tone.

\section{Location of Target Sites}

The location of the slow pathway in patients with atypical AVNRT appears to be near the coronary sinus os, in the posteroseptal area of the right atrium. This is similar to the location of the slow pathway in patients with typical AVNRT. ${ }^{2-5}$ This observation suggests that the anatomical substrate of the slow pathway is similar in patients with the typical and atypical forms of AVNRT.

\section{Limitations}

The conclusions of this study are limited by the small sample size and need to be confirmed in larger groups of patients. Second, the anatomical approach to ablation of the slow pathway ${ }^{5}$ was not evaluated and may also prove to be an effective approach to treating atypical AVNRT. Third, while possible slow pathway potentials were used to evaluate target sites in sinus rhythm, no attempt was made to validate these potentials using pacing techniques. ${ }^{3} \mathrm{~A}$ fourth limitation is that a follow-up electrophysiologic test was performed in only 3 of 10 patients. However, the 6 patients in whom a follow-up electrophysiologic test was not performed had experienced symptoms of tachycardia at least 2 to 3 times a week, and therefore clinical follow- up was felt to be adequate for assessing the outcome of the ablation procedures.

\section{Conclusions}

In conclusion, the slow pathway of atypical AVNRT can be successfully ablated by mapping during either sinus rhythm or tachycardia. In this small series of patients, a demonstrable advantage of mapping the location of the slow pathway in patients with atypical AVNRT during sinus rhythm as opposed to using retrograde atrial activation was not observed. However, the ability to use multicomponent atrial electrograms or possible slow pathway potentials recorded during sinus rhythm as the mapping technique to localize the slow pathway may be preferable for at least two reasons. First, catheter position is more stable when radiofrequency energy is applied during sinus rhythm than when radiofrequency energy is applied during PSVT. In the latter situation, a successful application of radiofrequency energy results in termination of PSVT and this may result in displacement of the ablation catheter before the slow pathway is destroyed. This rarely occurs when radiofrequency energy is applied during sinus rhythm. Second, the endpoint for mapping may be easier to recognize when looking for possible slow pathway potentials during sinus rhythm than when searching for the shortest VA time during tachycardia. Because retrograde atrial activation occurs through the slow pathway, the VA time at all potential target sites will be relatively long, making it 
more difficult to recognize the site at which the VA time is the shortest.

Acknowledgment: The authors greatly appreciate the excellent secretarial support provided by Ms. Heidi Williams.

\section{References}

1. Calkins H, Sousa J, El-Atassi R, et al: Diagnosis and cure of the Wolff-Parkinson-White syndrome or paroxysmal supraventricular tachycardias during a single electrophysiologic test. N Engl J Med 1991;324: 1612-1618.

2. Haissaguerre M, Gaita F, Fischer B, et al: Elimination of atrioventricular nodal reentrant tachycardia using discrete slow potentials to guide application of radiofrequency energy. Circulation 1992;85:21622175 .
3. Jackman WM, Beckman KJ, McClelland JH, et al: Treatment of supraventricular tachycardia due to atrioventricular nodal reentrant tachycardia by radiofrequency catheter ablation of slow-pathway conduction. N Engl J Med 1992;327:313-318.

4. Kay GN, Epstein AE, Dailey SM, et al: Selective radiofrequency ablation of the slow pathway for the treatment of atrioventricular nodal reentrant tachycardia. Evidence for involvement of perinodal myocardium within the reentrant circuit. Circulation 1992;85:1675-1688.

5. Jazayeri MR, Hempe SL, Sra JS, et al: Selective transcatheter ablation of the fast and slow pathways using radiofrequency energy in patients with atrioventricular nodal reentrant tachycardia. Circulation 1992;85:4: 1318-1328.

6. Leitch J, Klein GJ, Yee R, et al: Invasive electrophysiologic evaluation of patients with supraventricular tachycardia. Cardiol Clin 1990;8:465-477. 
This document is a scanned copy of a printed document. No warranty is given about the accuracy of the copy. Users should refer to the original published version of the material. 